\title{
Transcriptomic events associated with internal browning of apple during postharvest storage
}

Ifigeneia Mellidou', Kim Buts ${ }^{1}$, Darwish Hatoum¹, Quang Tri Ho ${ }^{1}$, Jason W Johnston ${ }^{6}$, Christopher B Watkins ${ }^{4}$, Robert J Schaffer ${ }^{6,7}$, Nigel E Gapper $^{4,5}$, Jim J Giovannoni ${ }^{5,8}$, David R Rudell ${ }^{3}$, Maarten LATM Hertog ${ }^{1 *}$ and Bart M Nicolai ${ }^{1,2}$

\begin{abstract}
Background: Postharvest ripening of apple (Malus $x$ domestica) can be slowed down by low temperatures, and a combination of low $\mathrm{O}_{2}$ and high $\mathrm{CO}_{2}$ levels. While this maintains the quality of most fruit, occasionally storage disorders such as flesh browning can occur. This study aimed to explore changes in the apple transcriptome associated with a flesh browning disorder related to controlled atmosphere storage using RNA-sequencing techniques. Samples from a browning-susceptible cultivar ('Braeburn') were stored for four months under controlled atmosphere. Based on a visual browning index, the inner and outer cortex of the stored apples was classified as healthy or affected tissue.

Results: Over 600 million short single-end reads were mapped onto the Malus consensus coding sequence set, and differences in the expression profiles between healthy and affected tissues were assessed to identify candidate genes associated with internal browning in a tissue-specific manner. Genes involved in lipid metabolism, secondary metabolism, and cell wall modifications were highly modified in the affected inner cortex, while energy-related and stress-related genes were mostly altered in the outer cortex. The expression levels of several of them were confirmed using qRT-PCR. Additionally, a set of novel browning-specific differentially expressed genes, including pyruvate dehydrogenase and 1-aminocyclopropane-1-carboxylate oxidase, was validated in apples stored for various periods at different controlled atmosphere conditions, giving rise to potential biomarkers associated with high risk of browning development.

Conclusions: The gene expression data presented in this study will help elucidate the molecular mechanism of browning development in apples at controlled atmosphere storage. A conceptual model, including energy-related (linked to the tricarboxylic acid cycle and the electron transport chain) and lipid-related genes (related to membrane alterations, and fatty acid oxidation), for browning development in apple is proposed, which may be relevant for future studies towards improving the postharvest life of apple.
\end{abstract}

Keywords: Apple fruit, Browning disorder, Metabolic pathways, Postharvest physiology, RNA sequencing, Transcriptomics

\section{Background}

After harvest, apples (Malus $\times$ domestica Borkh.) are typically stored under a controlled atmosphere $(\mathrm{CA})$ with reduced $\mathrm{O}_{2}$ and increased $\mathrm{CO}_{2}$ levels to extend their commercial storage life. A major problem of several apple cultivars during CA storage is the development of internal browning disorders. Depending on the disorder, incidence can be aggravated by low storage temperatures and CA

\footnotetext{
* Correspondence: maarten.hertog@biw.kuleuven.be

'Division of Mechatronics, Biostatistics and Sensors, Department of Biosystems (BIOSYST), KU Leuven, Willem de Croylaan 42, bus 2428, Leuven 3001, Belgium

Full list of author information is available at the end of the article
}

conditions, either high $\mathrm{CO}_{2}$, low $\mathrm{O}_{2}$, or a combination of the two. The 'Braeburn' apple cultivar is particularly susceptible to flesh browning, and at least two different expressions of the disorder have been identified. One is a dark discoloration that is initiated in the cortical flesh [1], while the other usually develops in the area near the seed cavities and may extend from the inner region near the core to the outer cortex (Additional file 1: Figure S1) [2].

Internal browning disorders have been extensively studied in pears [3-5], and apples [6,7]. Besides the various symptoms which may vary between species, cultivars, or CA conditions, browning can be associated with membrane damage 
resulting from stresses caused by low temperature, low $\mathrm{O}_{2}$ and/or elevated $\mathrm{CO}_{2}$ concentration during CA storage [7]. In gas-related disorders, oxidative stress can also be aggravated by the fruit geometry that induces additional gradients within the fruit, resulting in increased hypoxia towards the centre of the fruit [8-11]. This oxidative stress may in turn cause a shift of the cellular metabolism from the respiratory to the far less efficient fermentation pathway. As a result, less energy may become available to maintain membrane integrity under the constant stress of reactive oxygen species (ROS). Eventually, the loss of membrane integrity can lead to the disruption of cellular compartmentalisation, as has been shown by the leak of cellular liquid into the intracellular spaces, hence impeding diffusion of gases through tissue [7]. The release of phenolic compounds from the vacuole, and polyphenol oxidases (PPO) from the plastids, results in the enzymatic oxidation of phenols by PPOs to o-quinones and the formation of the brown-coloured pigment melanin [12]. A protective role for ${ }_{\mathrm{L}}$-ascorbic acid (AsA) has also been proposed, due to its ability to reduce quinones back to precursor phenols $[13,14]$.

The apple consensus genome ('Golden Delicious') has a relatively small size of $\sim 750 \mathrm{Mb}$ and 63,541 predicted genes [15]. Several RNA-sequencing (RNA-Seq) studies have been recently reported on apple, investigating tree architecture [16,17], pathogen infection [18], and $\mathrm{CO}_{2}$ injury during postharvest storage [19]. The goal of this study was to explore the apple transcriptome changes associated with flesh browning during storage of 'Braeburn' apple. Based on recent studies [10,11], gas gradients at the currently applied CA storage conditions indicate that the main trigger for browning development is likely the very low oxygen concentration in the inner cortex (below $0.5 \%$ ), and not the high $\mathrm{CO}_{2}$ concentrations as observed in other apple browning disorders.

In this manuscript, the RNA-Seq technology was used to explore transcriptomic events after four months of CA storage. Based on a visual browning index (BI), the inner and outer cortex of the stored apples was classified as healthy or affected tissue. Reads obtained were mapped against the Malus consensus coding sequence (CDS) set and browning-related differentially expressed genes (DEGs) were identified using multivariate statistical tools. Based on associations between expression levels of the candidate genes and browning incidence in fruit stored at various other storage conditions, potential biomarkers were suggested for assessing the risk of browning development.

\section{Results and discussion}

To obtain an overview of the browning-related transcriptomic changes, cDNA libraries of inner and outer cortex samples from four individual fruits collected at harvest and from 16 individual fruits collected after four months storage were designed for Illumina RNA-Seq. Over 640 million short single-end reads were generated (Additional file 2: Table S1), with each cDNA library containing on average 16 million high-quality reads (after trimming for low quality bases and sequences of less than 20 nucleotides). The mean reads mapping rate was $70.8 \pm 4.2 \%$ (Additional file 2: Table S1), of which $66.1 \pm 0.6 \%$ mapped uniquely against the predicted gene set [15]. Only $29.2 \%$ of the reads were not counted in the RNA-Seq mapping process. This reads mapping rate is considerably higher than those reported by other authors working with Malus (35.8\% of uniquely mapped reads according to [18]; $65 \%$ of total reads according to [19]). The total number of expressed genes was on average $30,816 \pm 1,346$ per sample or around $48.5 \%$ of the Malus predicted CDS set (Additional file 2: Table S1). A total of 25,287 and 22,464 expressed genes were found in all inner and outer cortex samples, respectively, with a total of 21,128 genes found in common (data not shown).

\section{Transcriptomic differences between healthy and affected tissues}

The initial 'Partial least squares discriminant analysis' (PLS-DA) model containing all genes revealed poor discrimination between healthy (low BI) and affected (high BI) fruit cortex. However, the final reduced models after jack-knifing, were able to explain $96 \%$ and $84 \%$ of variance between the two classes (healthy-affected) in the inner (containing 578 DEGs) and outer (containing 1456 DEGs) cortex, respectively. These sets of DEGs were filtered for fold change between healthy and affected tissues of either $>1.5$ or $<-1.5$, resulting in 357 (inner) and 560 (outer) DEGs. Finally, the DEGs were filtered to exclude those genes significantly up- or down-regulated with time independent of the incidence of browning (Additional file 2: Table S2). These were identified by comparing fruit at harvest to the healthy fruit after storage under the assumption these DEGs were more generally related to ripening. This resulted in the final set of 234 and 459 browning-specific DEGs in the inner and in the outer fruit cortex, respectively (Additional file 2: Tables S3, S4). Only five genes were in common when comparing DEGs from the inner and the outer cortex. Specifically, a disease resistance protein (MDP0000153857), a cyclin kinase (MDP0000722904), and an eukaryotic translation initiation factor (MDP0000378642) were induced in both cortex tissues of affected apples, whereas a nac domain-containing protein (MDP0000207408) and an uncharacterized protein (MDP0000299891) were repressed in the affected tissues. This limited overlap in transcriptomic events is indicative of the spatial differences in the regulation of browning potentially related to the spatial variation in gas conditions inside the fruit $[7,11]$.

GeneOntology (GO) analyses returned a blast hit for over $85.5 \%$ of the genes, and GO terms could be assigned 
to over $70 \%$ of these genes (data not shown). Overrepresentations of GO terms in the set of DEGs in affected tissues were evaluated to indicate which biological processes, molecular functions and cellular components were mostly affected by the disorder (Figure 1). Several significantly induced GO terms representing cellular components were associated with plastids and membranes for both affected inner and outer cortex (Figure 1A). This comes to no surprise as plastids in fruits are involved in fatty acid (FA) and isoprenoid synthesis, and in the generation of non-photosynthetic ATP and reducing power [20]. The biological processes significantly enriched in the set of induced DEGs in the affected inner cortex were the cellular (30.3\%) and metabolic processes (20.5\%). Other over-represented categories of biological processes included the biosynthetic (16.4\%), and carbohydrate metabolic processes (14.8\%), and stress responses (13.1\%). A significant set of DEGs were also related to the lipid metabolic process (7.38\%), signal transduction (5.74\%) and the generation of precursor metabolites and energy (3.28\%). Similar results were obtained for the outer cortex, with the main difference being the lower percentage of DEGs related to carbohydrate metabolic processes (6.11\%). The GO terms for molecular function up-regulated in affected inner and outer cortex included genes coding for proteins with catalytic or hydrolase activity, and for binding proteins (i.e., nucleotide-, protein-, zinc-, ATP-binding). The set of DEGs with hydrolase activity included several genes involved in the hydrolysis of membrane-related lipids/ phospholipids (Tables 1 and 2).

Under the cellular component category, many repressed DEGs in affected tissues were categorized as nucleus $(9.8 \%$ in inner, $9.1 \%$ in outer cortex) or plastids (8.0\% in inner, $10.9 \%$ in outer cortex), but in contrast to the set of induced DEGs, several differences were observed between the inner and the outer cortex (Figure 1B). In particular, genes associated to membrane, cytosol or vacuole seemed to be more repressed in the affected outer than the affected inner cortex. The top most abundant biological process categories significantly down-regulated in affected tissues included the cellular process $(27.7 \%$ in inner, $26.1 \%$ in outer cortex), the biosynthetic process (16.1\% in inner, $13.5 \%$ in outer cortex) and transport (15.2\% in inner, $10.4 \%$ in outer cortex). The most notable down-regulation of molecular functions in affected tissues were the numerous GO terms related to kinase activity.

The overall distribution of DEGs in the 35 MapMan bins/ pathways is summarized in Additional file 1: Figure S2, whereas an overview of the metabolic changes occurring in affected apple cortex is shown in Additional file 1: Figure S3. The most abundant DEGs were involved in stress $(6.67 \%$ in inner, $7.23 \%$ in outer cortex), signalling (6.67\% in inner, $4.82 \%$ in outer cortex), transport (4.31\% in inner, $4.62 \%$ in outer cortex), cell ( $4.71 \%$ in inner, $4.02 \%$ in

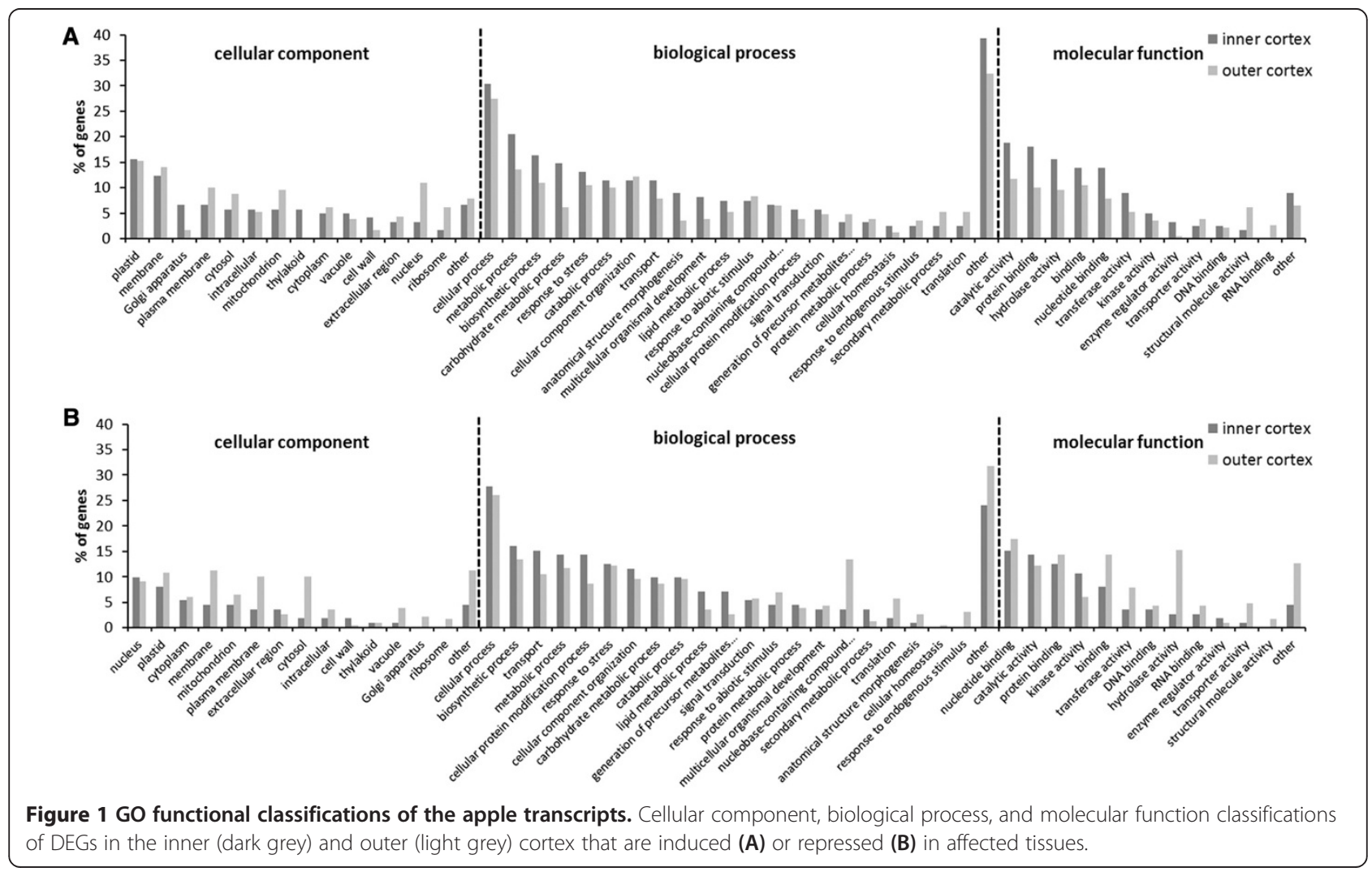


Table 1 Browning-related genes induced or repressed in the affected inner cortex of 'Braeburn' apples

\begin{tabular}{|c|c|c|c|c|c|c|}
\hline \multirow[b]{2}{*}{ Malus ID } & \multirow[b]{2}{*}{ Gene description } & \multirow[b]{2}{*}{ Function } & \multirow[b]{2}{*}{ p-value } & \multicolumn{2}{|l|}{ RPKM } & \multirow[b]{2}{*}{$\begin{array}{l}\text { Fold } \\
\text { change }\end{array}$} \\
\hline & & & & Healthy & Affected & \\
\hline \multicolumn{7}{|c|}{ Energy-related pathways } \\
\hline MDP0000192364 & Pyruvate dehydrogenase & Link glycolysis to TCA & $<0.001$ & 14.53 & 29.39 & 2.02 \\
\hline MDP0000129305 & Phosphoglycerate mutase & Glycolysis/dually targeted & 0.016 & 0.91 & 1.80 & 1.98 \\
\hline MDP0000295823 & Probable lactate/malate dehydrogenase & Fermentation & $<0.001$ & 20.06 & 30.24 & 1.51 \\
\hline MDP0000622920 & Phosphoenolpyruvate carboxylase & TCA/org transformation & 0.004 & 8.35 & 5.47 & -1.53 \\
\hline MDP0000198410 & Aconitate hydratase & TCA/org transformation & 0.016 & 19.75 & 11.72 & -1.69 \\
\hline MDP0000798440 & Cytochrome $\mathrm{c}$ biogenesis $\mathrm{fn}$ & $\begin{array}{l}\text { Mitochondrial electron transport/ATP } \\
\text { synthesis }\end{array}$ & 0.014 & 2.67 & 1.52 & -1.76 \\
\hline \multicolumn{7}{|l|}{ Lipid metabolism } \\
\hline MDP0000249250 & Phospholipase a2 & Lipid degradation & 0.004 & 0.49 & 4.25 & 8.65 \\
\hline MDP0000576682* & Butyrate- ligase peroxisomal-like & FA synthesis and FA elongation & 0.01 & 0.20 & 1.30 & 6.63 \\
\hline MDP0000794484 & Alpha/beta-Hydrolase & Lipid degradation & 0.003 & 2.60 & 6.33 & 2.43 \\
\hline MDP0000833444 & Diacylglycerol kinase-like & Phospholipid synthesis & 0.018 & 2.14 & 5.15 & 2.41 \\
\hline MDP0000309977 & Acyl-coenzyme a thioesterase & Lipid degradation/beta-oxidation & 0.004 & 0.95 & 2.23 & 2.36 \\
\hline MDP0000849585 & Alpha/beta-Hydrolase & Lipid degradation & 0.009 & 2.85 & 5.69 & 2.00 \\
\hline MDP0000283158 & Alpha beta-hydrolase, lipase & Lipid degradation & $<0.001$ & 4.51 & 7.92 & 1.76 \\
\hline MDP0000273425 & Diacylglycerol kinase-like & Phospholipid synthesis & 0.04 & 4.44 & 2.73 & -1.63 \\
\hline \multicolumn{7}{|l|}{ Redox state } \\
\hline MDP0000615196 & Glutaredoxin family protein & Redox state & $<0.001$ & 0.32 & 1.18 & 3.64 \\
\hline MDP0000146621 & Nadh-cytochrome b5 reductase & Redox state & 0.004 & 4.39 & 8.03 & 1.83 \\
\hline MDP0000196554 & Chorismate mutase/APX & Aminoacid synthesis/ascorbate metabolism & $<0.001$ & 11.63 & 19.96 & 1.72 \\
\hline MDP0000251669 & Thioredoxin & Redox state & 0.019 & 18.00 & 28.15 & 1.56 \\
\hline MDP0000252195 & Ferredoxin-thioredoxin reductase & Redox state & $<0.001$ & 10.84 & 16.70 & 1.54 \\
\hline MDP0000520089* & Desacetoxyvindoline 4- & Ascorbate and glutathione metabolism & 0.041 & 5.41 & 3.53 & -1.53 \\
\hline MDP0000181414 & $\begin{array}{l}\text { Alpha-ketoglutarate-dependent } \\
\text { dioxygenase }\end{array}$ & Redox state & 0.004 & 6.69 & 4.16 & -1.61 \\
\hline \multicolumn{7}{|c|}{ Secondary metabolism } \\
\hline MDP0000260512 & 4-coumarate: ligase & Phenylpropanoids & 0.001 & 0.16 & 1.05 & 6.71 \\
\hline MDP0000576682* & Butyrate- ligase peroxisomal-like & Sulfur-containing glucosinolates synthesis & 0.01 & 0.20 & 1.30 & 6.63 \\
\hline MDP0000206680 & Reticuline oxidase-like & Alkaloid-like & $<0.001$ & 1.48 & 5.13 & 3.45 \\
\hline MDP0000702557* & UDP-glucuronosyl/UDP-glucosyltransferase & Flavonoids/flavonols synthesis & 0.001 & 30.37 & 48.24 & 1.59 \\
\hline MDP0000520089* & Desacetoxyvindoline 4- & Sulfur-containing glucosinolates synthesis & 0.041 & 5.41 & 3.53 & -1.53 \\
\hline \multicolumn{7}{|l|}{ Cell wall } \\
\hline MDP0000610961 & L-ascorbate oxidase & Cell wall modifications & $<0.001$ & 30.35 & 132.43 & 4.36 \\
\hline MDP0000873667 & $\begin{array}{l}\text { Xyloglucan endotransglucosylase/ } \\
\text { hydrolase }\end{array}$ & Cell wall modification & $<0.001$ & 52.59 & 229.40 & 4.36 \\
\hline MDP0000904458 & Fasciclin-like arabinogalactan & Cell wall proteins & $<0.001$ & 193.78 & 525.70 & 2.71 \\
\hline MDP0000723275 & Arabinose 5-phosphate isomerase & Cell wall precursor synthesis & $<0.001$ & 18.80 & 32.91 & 1.75 \\
\hline MDP0000289339 & Cellulose synthase & Cell wall cellulose synthesis & 0.013 & 1.90 & 1.03 & -1.85 \\
\hline MDP0000836165 & Pectin methylesterase inhibitor & Cell wall pectin esterases & 0.036 & 2.42 & 1.21 & -2.00 \\
\hline MDP0000616949 & Pectin methylesterase inhibitor & Cell wall pectin esterases & 0.01 & 1.04 & 0.44 & -2.37 \\
\hline
\end{tabular}

P-values for DEGs between healthy and affected apples were calculated using PLS-DA, where gene expression values (RPKM) were used as predictor variables and the two class distinctions as response variables. Blast2GO and Mercator web tools were used for gene description and gene function analysis.

*Genes that have been assigned to more than one metabolic pathways. 
Table 2 Browning-related genes induced or repressed in the affected outer cortex of 'Braeburn' apples

\begin{tabular}{|c|c|c|c|c|c|c|}
\hline \multirow[b]{2}{*}{ Malus ID } & \multirow[b]{2}{*}{ Gene description } & \multirow[b]{2}{*}{ Function } & \multirow[b]{2}{*}{ p-value } & \multicolumn{2}{|l|}{ RPKM } & \multirow[b]{2}{*}{$\begin{array}{l}\text { Fold } \\
\text { change }\end{array}$} \\
\hline & & & & Healthy & Affected & \\
\hline \multicolumn{7}{|c|}{ Energy-related pathways } \\
\hline MDP0000158797 & $\begin{array}{l}\text { Bisphosphoglycerate-independent } \\
\text { phosphoglycerate mutase }\end{array}$ & Glycolysis cytosolic branch & 0.015 & 1.67 & 4.25 & 2.54 \\
\hline MDP0000149088 & Ubiquinone biosynthesis protein coq4 & Mitochondrial electron transport/ATP synthesis & 0.01 & 3.59 & 6.55 & 1.82 \\
\hline MDP0000251581 & Succinate dehydrogenase & TCA/org transformation & 0.003 & 25.49 & 42.53 & 1.67 \\
\hline MDP0000376244 & Pyruvate kinase & glycolysis cytosolic branch & 0.006 & 80.59 & 125.23 & 1.55 \\
\hline MDP0000807498 & Cytochrome b-cl complex & mitochondrial electron transport/ATP synthesis & 0.008 & 32.39 & 49.30 & 1.52 \\
\hline MDP0000134766 & Ubiquinol-cytochrome c reductase & mitochondrial electron transport/ATP synthesis & 0.016 & 33.28 & 50.20 & 1.51 \\
\hline MDP0000163886 & Aconitate hydratase & TCA/org transformation & $<0.001$ & 34.74 & 23.14 & -1.50 \\
\hline MDP0000141199 & Malate dehydrogenase & TCA/org transformation & 0.01 & 68.62 & 45.82 & -1.50 \\
\hline MDP0000581903 & $\begin{array}{l}\text { Glyceraldehyde 3-phosphate } \\
\text { dehydrogenase }\end{array}$ & Glycolysis cytosolic branch & 0.012 & 142.56 & 93.35 & -1.53 \\
\hline MDP0000120718 & atp-citrate synthase & TCA/org transformation & $<0.001$ & 82.25 & 53.31 & -1.54 \\
\hline MDP0000631825 & Pyruvate kinase isozyme chloroplastic-like & Glycolysis plastid branch & 0.005 & 13.34 & 8.44 & -1.58 \\
\hline MDP0000168246 & atp-citrate synthase & TCA/org transformation & 0.016 & 11.77 & 7.05 & -1.67 \\
\hline MDP0000743397 & Pyruvate kinase cytosolic & Glycolysis cytosolic branch & 0.039 & 12.05 & 6.33 & -1.90 \\
\hline MDP0000119941 & Dihydrolipoyl dehydrogenase & PDH complex & 0.048 & 3.46 & 1.76 & -1.97 \\
\hline MDP0000677354 & Alcohol dehydrogenase & Fermentation & $<0.000$ & 7.30 & 3.32 & -2.20 \\
\hline MDP0000186461 & Alcohol dehydrogenase & Fermentation & $<0.001$ & 5.52 & 2.33 & -2.37 \\
\hline MDP0000746317 & Coenzyme Q biosynthesis coq4 & Mitochondrial electron transport/ATP synthesis & 0.003 & 2.04 & 0.72 & -2.85 \\
\hline \multicolumn{7}{|l|}{ Lipid metabolism } \\
\hline MDP0000235803 & Phospholipase c & Lipid degradation & 0.026 & 0.17 & 1.13 & 6.56 \\
\hline MDP0000293806 & Acyl CoA oxidase & Lipid degradation/beta-oxidation & 0.049 & 0.75 & 1.34 & 1.78 \\
\hline MDP0000270312 & $\begin{array}{l}\text { Neutral/alkaline non-lysosomal } \\
\text { ceramidase }\end{array}$ & Exotics' (steroids, squalene etc.) sphingolipids & 0.002 & 2.81 & 4.71 & 1.68 \\
\hline MDP0000847523 & Acyl-CoA thioesterase & Lipid degradation/beta-oxidation & 0.008 & 5.30 & 8.86 & 1.67 \\
\hline MDP0000190112 & Serine C-palmitoyltransferase & Exotics' (steroids, squalene etc.) sphingolipids & 0.047 & 1.36 & 2.27 & 1.66 \\
\hline MDP0000084546* & Cycloartenol synthase & Exotics' (steroids, squalene etc.) & 0.002 & 1.47 & 2.21 & 1.51 \\
\hline MDP0000209755 & Enoyl CoA hydratase & Lipid degradation/beta-oxidation & 0.007 & 4.52 & 2.71 & -1.67 \\
\hline MDP0000422184 & Sphingosine-1-phosphate lyase & Exotics' (steroids, squalene etc.) sphingolipids & 0.028 & 10.76 & 6.40 & -1.68 \\
\hline \multicolumn{7}{|l|}{ Redox state } \\
\hline MDP0000508761 & $\begin{array}{l}\text { Flavonol synthase flavanone } \\
\text { 3-hydroxylase-like }\end{array}$ & Redox state/flavonoid biosynthesis & 0.015 & 0.57 & 1.27 & 2.23 \\
\hline MDP0000364366 & Superoxide dismutase & Redox state/dismutases and catalases & 0.016 & 19.44 & 30.52 & 1.57 \\
\hline MDP0000699607 & Catalase & Redox state/dismutases and catalases & 0.035 & 53.52 & 80.67 & 1.51 \\
\hline MDP0000217438 & L-galactose-1-phosphate phosphatase & Ascorbate biosynthesis & 0.006 & 17.14 & 11.24 & -1.52 \\
\hline MDP0000203927 & Glutathione peroxidase & Ascorbate and glutathione metabolism & $<0.001$ & 49.07 & 22.51 & -2.18 \\
\hline \multicolumn{7}{|c|}{ Secondary metabolism } \\
\hline MDP0000639264 & $\begin{array}{l}3 \text {-n-debenzoyl-2 -deoxytaxol } \\
\text { n-benzoyltransferase }\end{array}$ & Phenylpropanoids & 0.005 & 1.48 & 2.64 & 1.79 \\
\hline MDP0000312032 & $\begin{array}{l}\text { 3-hydroxy-3-methylglutaryl } \\
\text { coenzyme a reductase }\end{array}$ & isoprenoids/mevalonate pathway & 0.009 & 21.49 & 32.33 & 1.50 \\
\hline MDP0000269612 & Cinnamoyl- reductase & phenylpropanoids/lignin biosynthesis & 0.002 & 210.28 & 315.08 & 1.50 \\
\hline MDP0000157996 & $\begin{array}{l}\text { 3-hydroxy-3-methylglutaryl } \\
\text { coenzyme a reductase }\end{array}$ & isoprenoids/mevalonate pathway & 0.018 & 3.72 & 1.94 & -1.92 \\
\hline
\end{tabular}


Table 2 Browning-related genes induced or repressed in the affected outer cortex of 'Braeburn' apples (Continued)

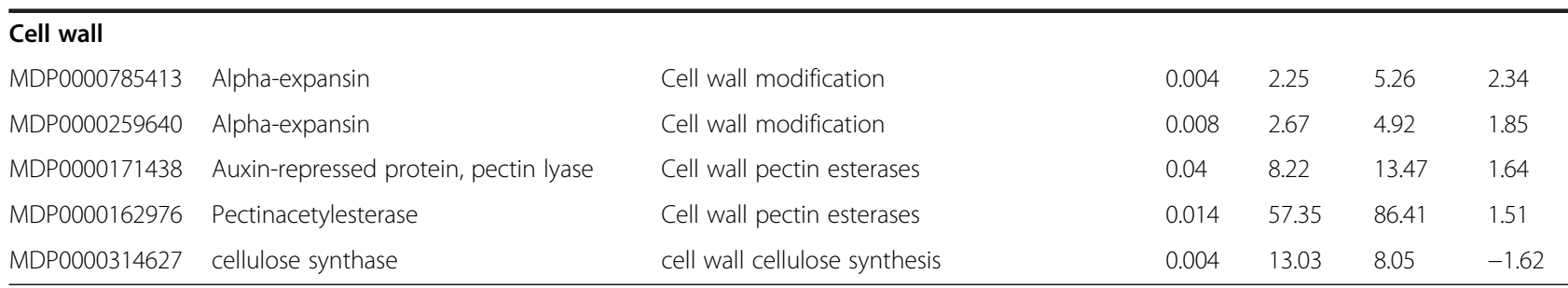

P-values for the differentially expressed genes between healthy and affected apples were calculated using PLS-DA, where gene expression values (RPKM) were used as predictor variables and the two class distinctions as response variables. Blast2GO and Mercator web tools were used for gene description and gene function analysis.

*Genes that have been assigned to more than one metabolic pathways.

outer cortex), lipids (3.14\% in inner, $1.81 \%$ in outer cortex), energy ( $1.95 \%$ in inner, $3.60 \%$ in outer cortex), and redox state $(2.35 \%$ in inner, $1.00 \%$ in outer cortex) pathways. The discussion of these results focuses on pathways expected to be involved or influenced by browning development at CA conditions, such as energy-related, lipid metabolism, cell wall modifications, redox state, and secondary metabolism (Figure 2, Tables 1 and 2). Furthermore, a close correlation $\left(R^{2}=0.95\right)$ was observed between log2-fold changes measured by RNA-Seq and real-time quantitative PCR (qRTPCR; Figure 3) on a selection of 15 DEGs (Additional file 2: Table S5), indicating that fold-change values obtained from sequencing are accurate.

\section{Candidate genes for browning development}

The different transcriptomic responses in the inner and outer cortex should be interpreted against the spatially different gas conditions inside the fruit. Due to the fruit's geometry and the properties of the different fruit tissues (e.g., peel, and cortex), internal gas gradients will develop $[7,9,10]$. As a result hypoxic stress will increase when moving from the outer towards the inner cortex. Based on the work presented by [11], simulations were performed for a typical 'Braeburn' apple exposed to the currently applied CA storage conditions $\left(3 \% \mathrm{O}_{2}\right.$ and $0.7 \% \mathrm{CO}_{2}$ ) indicating that the expected $\mathrm{O}_{2}$ levels at the position of the outer and inner cortex were around 1.6\% and $0.5 \%$ respectively (Figure $4 \mathrm{~A}$ ). Additionally, the expected $\mathrm{CO}_{2}$ levels at the inner and outer cortex were around $0.7 \%$ and $1.1 \%$, respectively (data not shown), suggesting that $\mathrm{CO}_{2}$ was not the trigger for the development of the disorder. Given these expected gas gradients, the identified DEGs are discussed separately to highlight tissue-specific responses to low $\mathrm{O}_{2}$ stress.

\section{Genes involved in energy-related pathways}

Plant cells synthesize energy-rich molecules like ATP and reductive power (NADH) via pathways such as photosynthesis, glycolysis, the tricarboxylic acid (TCA) cycle, and the mitochondrial electron transport chain (ETC.). An inhibition or a deficiency in one or more intermediates of these pathways may cause a wide range of

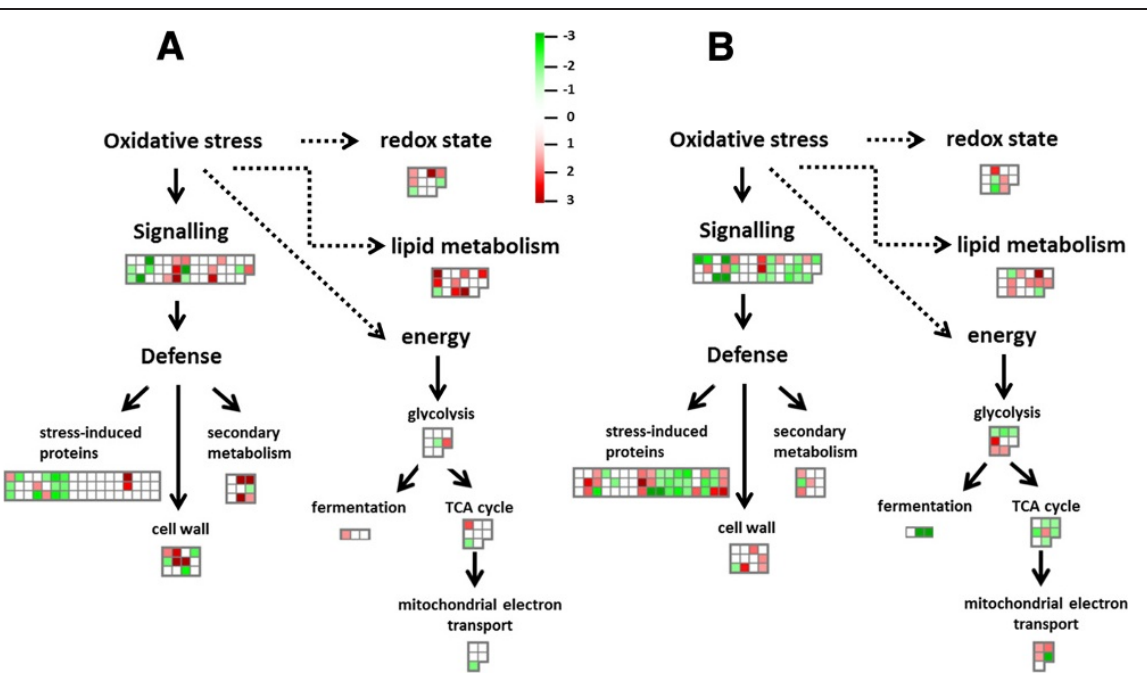

Figure 2 MapMan overview of DEGs from selected pathways between healthy and affected tissues (A. inner cortex; B. outer cortex). Induced genes in affected tissues are indicated in red and repressed genes in green. The scale bar displays changes in gene expression as fold change that were significant $(p<0.05)$ between the two class distinctions as indicated by PLS-DA. ABA: abscisic acid, TCA: tricarboxylic acid. 


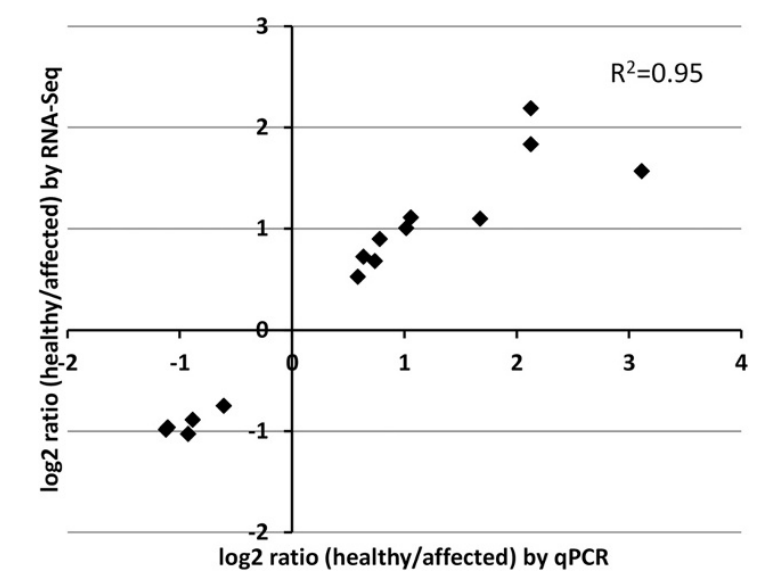

Figure 3 Correlation between RNA-Seq and qRT-PCR (as log2 ratio of relative expression of healthy/affected tissue). The relative expression levels of the selected genes (Additional file 2: Table S5) were obtained by RNA-Seq data and by qRT-PCR. The Pearson correlation coefficient is shown.

metabolic disturbances leading to postharvest disorders. In this study, several DEGs between healthy and affected tissues were linked to the energy-related pathways. This may be related to the loss of membrane integrity due to the prolonged exposure to low $\mathrm{O}_{2}$ levels at low temperature (discussed below). Under such circumstances, cells need to synthesize protective compounds to maintain their cellular compartmentalisation, and to detoxify metabolic intermediates accumulated. Indeed, the RNA-Seq results provided evidence of changes in all parts of the respiratory pathways of affected tissues (Tables 1 and 2; Figure 2), with the different cortex locations balancing their energy needs in a different manner.

Apart from the synthesis of ATP and NADH, glycolysis also serves to supply pyruvate to the mitochondrial TCA cycle. Overall, RNA-Seq data reveals a putative induction of glycolysis only in the affected inner cortex. Given the inner cortex of the fruit is exposed to lower $\mathrm{O}_{2}$ levels as compared to the outer cortex (Figure 4A), this is in agreement with recent findings from Ampofo et al. (personal communication) showing a clear up-regulation of the glycolysis in tomato cells when lowering $\mathrm{O}_{2}$ levels. This was interpreted as a cellular effort to maintain the overall energy supply in spite of the hypoxic stress limiting the ATP yield of the ETC. Phosphoglyceratemutase (PMG), previously proposed as the key gene controlling glycolysis in potato [21], showed significant induction in both the affected inner (MDP0000129305) and outer cortex (MDP 0000158797). No other glycolytic genes were changed in the affected inner cortex, whereas the expression of an abundant pyruvate kinase ( $P K$, MDP0000376244) was increased in the affected outer cortex. Nevertheless, two other members of the same gene family (cytosolic, MDP
0000743397; plastid, MDP0000631825) were significantly repressed, indicating the complex regulation of the pathway in different organelles. The highly abundant glyceraldehyde 3-phosphate dehydrogenase (MDP0000581903) was only repressed in the affected outer cortex. Putative fermentation-related genes were induced $(1.5$-fold) in the affected inner cortex (lactate/malate dehydrogenase, MDP 0000295823), but repressed more than 2.2-fold in the affected outer cortex (alcohol dehydrogenase, $A D H$; MDP 0000186461, MDP0000677354). This is in agreement with the expected $\mathrm{O}_{2}$ profiles in apple with the stronger hypoxia in the inner cortex triggering anaerobic metabolism.

Under aerobic conditions, the respiratory mechanism continues with the TCA cycle reactions in two ways. First, pyruvate produced in glycolysis can be transported to mitochondria where it is irreversibly oxidized to acetyl-CoA and $\mathrm{CO}_{2}$ by pyruvate dehydrogenase (PDH). This gene is thought to be the key step to regulate fluxes through the TCA cycle [22]. Secondly, phosphoenolpyruvate is converted to malate and/or pyruvate by cytosolic phosphoenolpyruvate carboxylase (PEPC), and then transferred to mitochondria. In the affected inner cortex, $P D H$ (MDP0000192364) was significantly induced and PEPC (MDP0000622920) repressed, suggesting an induction of the first path towards the TCA cycle. Although none of these genes changed significantly in the outer cortex, a putative dihydrolipoyl dehydrogenase (MDP0000119941), which is part of the PDH complex, was repressed. Acetyl-CoA enters the TCA cycle by condensation with oxaloacetate to form citric acid, which is 'recycled' back to oxaloacetate in a series of successive reactions, with the concomitant production of flavin adenine dinucleotide $\left(\mathrm{FADH}_{2}\right)$ and $\mathrm{NADH}$. With lowering $\mathrm{O}_{2}$ levels, TCA slows down, and glycolysis becomes the sole source of energy until the activation of fermentation. Indeed, the results suggested a down-regulation of the TCA cycle, particularly at the outer cortex (Figure 2). Specifically, aconitase hydratase (MDP0000198410, MDP0000163886) was significantly repressed at both cortex locations. As this enzyme is assumed to be sensitive to oxidative stress and regulated by iron availability [23], it could serve as a 'stress marker'. On the other hand, malate dehydrogenase ( $M D H$, MDP0000141199), and citrate synthase (CS, MDP0000168246, MDP0000120718), were only repressed in the outer cortex. Both $M D H$ and $C S$ can be inhibited by oxidized lipids such as polyunsaturated FAs generated under oxidative stress [24].

The reducing power produced through the previous steps can be used in the ETC. to drive ATP synthesis. Succinate dehydrogenase $(S D H)$ plays a dual role in both the TCA cycle and the ETC. Knock-out mutations in plants resulted in far-reaching perturbations in organic acids levels, photosynthesis, respiration rates and mitochondrial ROS generation [25]. An abundant SDH 
A

B
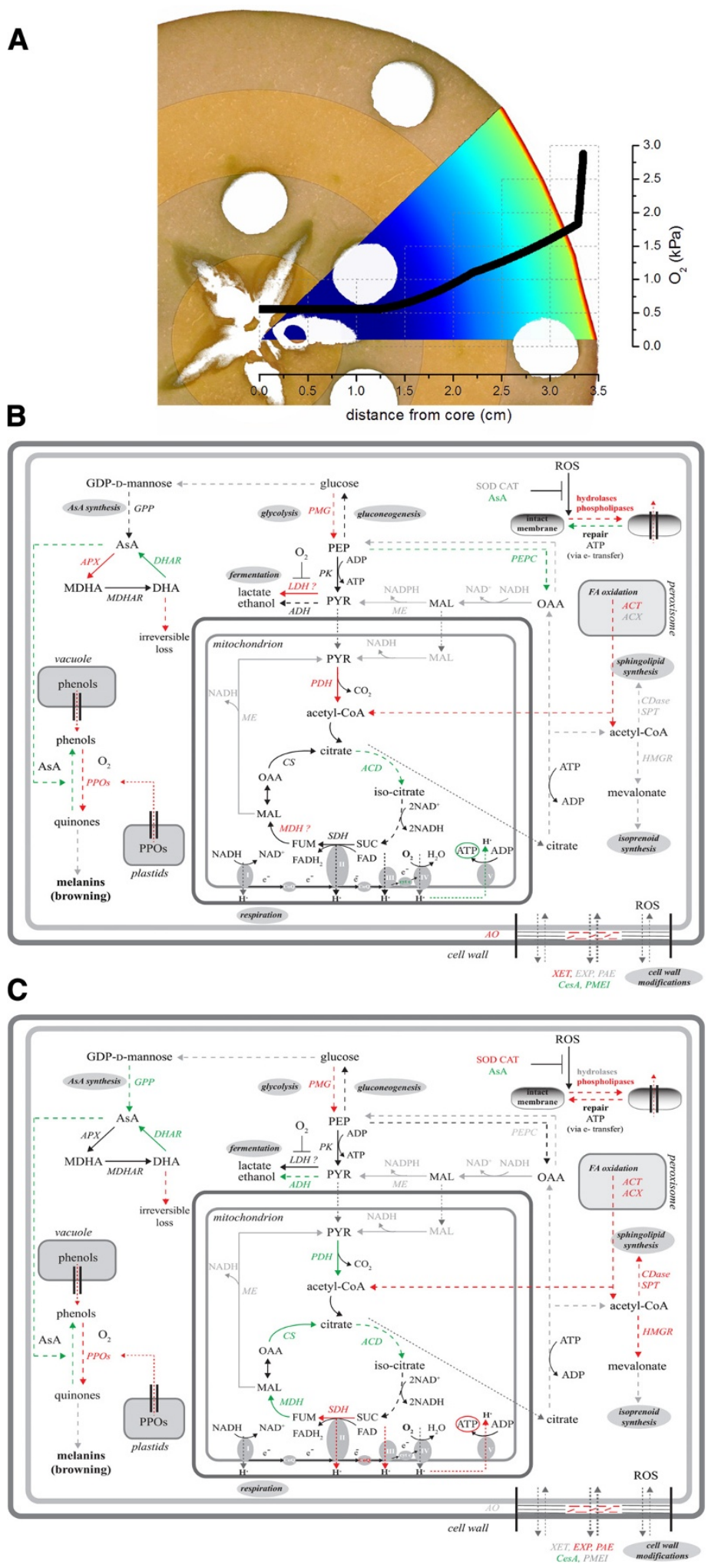

Figure 4 (See legend on next page.) 


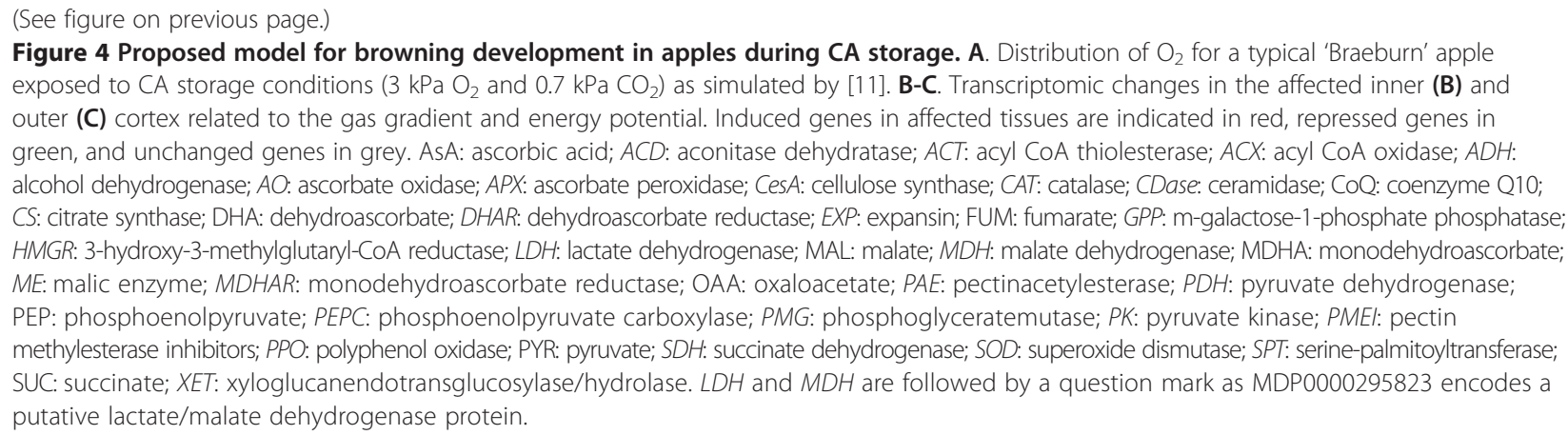

(MDP0000251581) was significantly induced in the affected outer cortex (Table 2), but remained unchanged in the inner part. Kinetic results indicated that $S D H$ depends on the ubiquinone reduction levels, and is activated by ATP [26]. An ubiquinol-cytochrome c reductase (MDP0000134766) was indeed induced in the affected outer cortex, whereas another two genes from the mitochondrial ETC. (ubiquinone biosynthesis protein coenzyme Q10, MDP0000149088; cytochrome b-c1 complex, MDP0000807498) were also up-regulated (Table 2). By contrast, the ETC. in the affected inner cortex was possibly down-regulated (repression of a cytochrome c biogenesis protein, MDP0000798440), suggesting that less energy was available to maintain membrane integrity.

\section{Genes involved in lipid metabolism}

During long-term CA storage, fruits need sophisticated mechanisms to tolerate oxidative stress, to guarantee ample energy production and to maintain membrane integrity. In total, 16 lipid-related DEGs, most of them encoding key enzymes of lipid degradation pathways, were identified in the affected tissues (Tables 1 and 2). Changes were more severe in the inner cortex as indicated by the higher fold-change (Figure 2). This confirms the membrane lipid alterations in the affected tissue similar to pears [27].

Phospholipids serve as signal transduction molecules under stress conditions, such as cold and hypoxia [28]. Phospholipase a2 (inner, PLA2, MDP0000249250) and phospholipase c (outer, MDP0000235803) were among the top up-regulated genes, with affected tissues having 8.7- or 6.6-fold higher expression than healthy tissues, respectively. Alterations in the expression of phospholipases may have activated phospholipid signalling in response to CA-induced stress. Additionally, alpha/ beta-hydrolases (MDP0000794484, MDP0000849585 and MDP0000283158) were induced in the affected inner cortex, probably indicating the more extended alterations in membrane integrity occurring there.

Peroxisomal FA beta-oxidation has multiple roles in plants, generating the substrate (acetyl-CoA) for the synthesis of isoprenoids, flavonoids, and FAs, as well as providing the respiratory substrate under carbohydratedepleted stress conditions [29]. An acyl-CoA thioesterase $(A C T)$ was induced in both tissues (inner, MDP0000309977; outer, MDP0000847523), whereas an acyl-CoA oxidase ( $A C X$, MDP0000293806) was only induced in the outer cortex. These results indicate a possible induction of the peroxisomal FA oxidation in the affected tissues at CA storage affecting lipid turnover.

Two other lipid-related genes, involved in FA synthesis (butyrate-ligase, MDP0000576682) and in phospholipid synthesis (diacylglycerol kinase-like, MDP0000833444) were significantly up-regulated in the affected inner cortex. By contrast, two genes involved in the sphingolipid metabolism (neutral/alkaline non-lysosomalceramidase, MDP0000270312; serine C-palmitoyltransferase, MDP000 0190112) and a gene of the steroid biosynthetic pathway (cycloartenol synthase; MDP0000084546) were significantly induced in the affected outer cortex. Sphingolipids comprise a major class of lipid signalling molecules in all eukaryotic cells having roles in mediating programmed cell death associated with plant defence [30]. Only few genes were down-regulated in the affected tissues, including a diacylglycerol kinase (MDP0000273425) in the inner cortex, as well as an enoyl CoA hydratase (MDP0000209755) and a sphingosine-1-phosphate lyase (MDP0000422184) in the outer cortex.

\section{Genes involved in redox state}

Internal browning in apple involves multiple oxidationreduction processes and accumulation of various antioxidant enzymes to cope with the overproduction of ROS induced by the low $\mathrm{O}_{2}$ stress. Seven DEGs were assigned as ROS scavengers in the inner cortex, including large families such as thioredoxins (MDP0000251669), glutaredoxins (MDP0000615196), and ferredoxin-thioredoxin reductases (MDP000025219), and five in the outer cortex, including glutathione peroxidase (MDP0000203927).

One of the most intriguing DEG in the inner cortex was a chorismate mutase (CM; MDP0000196554), 
which, apart from functioning in the aromatic amino acid synthesis, also has ascorbate peroxidase (APX) activity. Ascorbate peroxidase participates in the ascorbate-glutathione cycle scavenging $\mathrm{H}_{2} \mathrm{O}_{2}$ and recycling AsA in the cells [31]. Here, the expression of $A P X$ was high in the affected inner cortex, suggesting that the defence path has been triggered by the ROS burst. Nevertheless, if the AsA recycling pathway does not work efficiently, once oxidized to dehydroascorbic acid (DHA), AsA is no longer available. The current results showed a significant decrease in seven (inner cortex) or five (outer cortex) out of the ten Malus dehydroascorbate reductase (DHAR) genes with the rest remaining unchanged (Additional file 2: Table S6), indicating the malfunction of the cycle, and thus the incapacity to properly recycle AsA. DHAR has been identified as the key gene linked to susceptibility to flesh browning after cut [32]. Consequently, AsA content is expected to be low in both cortex locations. Low fruit AsA content has been associated to an increased susceptibility to browning in apples [33] and pears [3]. The importance of the AsA metabolism is further supported by the enhanced ${ }_{L}$-galactose-1-phosphate phosphatase (GPP, MDP0000217438) in the healthy outer cortex. This gene is involved in the main AsA biosynthetic pathway via ${ }_{L}$-galactose, and is considered as a key step of the pathway under stress in tomato fruit [34].

Superoxide dismutase (SOD) is an important antioxidant enzyme catalysing the dismutation of superoxide to $\mathrm{O}_{2}$ and $\mathrm{H}_{2} \mathrm{O}_{2}$. Meanwhile, $\mathrm{H}_{2} \mathrm{O}_{2}$ can be either indirectly scavenged by the AsA recycling pathway, or it can be directly reduced to water and $\mathrm{O}_{2}$ by catalase (CAT). Here, the expression of the abundant SOD (MDP0000364366) and CAT (MDP0000699607) was significantly up-regulated in the affected outer cortex to withstand the high ROS burst, dissimilar to the inner part where browning has already progressed and cell death processes may have been irreversibly triggered. Recent proteomic studies on apple ripening also demonstrated that SOD may have a major role in the redox state system during ripening and senescence [35]. When considering the whole fruit, the upregulated DEGs in the affected outer cortex may be good indicators of browning incidence in the inner part of the fruit.

\section{Genes involved in secondary metabolism}

Secondary metabolism (SM) plays a key role in the protection of plants against (a)biotic stresses. Several genes related to SM showed differential expression during storage (e.g. chorismate mutase, peroxidases; Additional file 2: Tables S3-S4), suggesting a shift from the primary to the SM and possible perturbations in the overall fruit metabolism and signal-transduction. Genes related to the major SM classes (phenylpropanoids, terpenoids/isoprenoids, and alkaloids/glucosinolates) were differentially expressed in affected tissues
(Tables 1 and 2), but the induction was higher in the inner cortex (Figure 2). Through the phenylpropanoid pathway, several defence-related metabolites can be produced, including flavonoids, and lignins. A 4-coumarate: ligase (MDP0000260512), which catalyses the last step of the phenylpropanoid pathway leading either to lignins or to flavonoids, was significantly induced (6.7-fold) in the inner cortex. By contrast, an abundant cinnamoylreductase (MDP0000269612) from the lignin biosynthetic pathway was induced in affected outer cortex. Although the link between an induction of lignification and internal browning is poorly understood, a negative correlation between lignin content and browning incidence of apple fruit infected by Penicillium expansum has been reported [36].

The first committed and rate-limiting step in the mevalonate pathway for isoprenoid biosynthesis is catalysed by 3-hydroxy-3-methylglutaryl-CoA reductase (HMGR), and modulated by many endogenous and external stimuli [37]. The abundant HMGR (MDP0000312032) was significantly induced in the outer affected cortex, whereas another one with low expression [reads per kilobase of exon per million mapped reads (RPKM) <4] was repressed (MDP0000157996). It has been reported that the induction of $H M G R$ during storage can be involved in the accumulation of $\alpha$-farnesene in apple skin, a compound related to the post-harvest disorder of superficial scald [38]. Other gene expressions altered in the affected tissues were related to flavonoid, glucosinolates or alkaloid synthesis (Tables 1 and 2), although their exact function is still poorly understood. The overexpression of genes related to flavonoid accumulation can be explained as the effort of affected tissues to balance out the oxidative stress synthetizing compounds with antioxidative properties, as already reported during the development of apple superficial scald [39].

\section{Genes involved in cell wall modifications}

A clear interaction between fruit softening and browning development was indicated in this study, such that a higher up-regulation of the cell wall modification paths occurred in the affected inner cortex (Figure 2). Ascorbate oxidase (AO) is an apoplastic enzyme linked to cell wall modifications, controlling the redox state of the apoplastic AsA pool and regulating stress perception and signal transduction [40]. An abundant $A O$ (MDP0000610961) was significantly induced (4.4-fold) in the affected inner cortex, suggesting a role in browning. The product of apoplastic oxidation of AsA by AO, DHA, is transported to the cytosol, where it can be recycled by the ascorbate-glutathione cycle [31]. Given that $D H A R$ was down-regulated (Additional file 2: Table S6), it is suggested that AsA may be irreversibly oxidized, enabling browning to occur. 
Several genes involved in cell wall loosening were induced in affected tissues. Xyloglucanendotransglucosylase/ hydrolase (XET; MDP0000873667), that is involved in the breakdown of hemicelluloses [41], was induced in the affected inner cortex. The activity of this enzyme coincides with the initial slow softening phase of postharvest apple fruit softening [42]. Alpha-expansin (EXP; MDP0000785413, MDP0000259640) also showed high expression in the affected outer cortex. An increased expression of both XETs and EXPs has been implicated in aril breakdown of longan (Dimocarpus longan) fruit stored at low temperature [43]. Two cell wall pectin esterases, an auxin-repressed pectin-lyase (MDP0000171438) and a pectinacetylesterase (MDP0000162976) were induced in the affected outer cortex. Pectatelyases catalyse the eliminative cleavage of de-esterified pectin, and have multiple functions, not only in pathogen attack, but also in various developmental processes including ripening and softening [44]. Apart from cell wall loosening related genes, a fasciclin-like arabinogalactan (MDP0000904458) and an arabinose 5-phosphate isomerase (MDP0000723275) were also induced in the affected inner cortex. Fasciclin-like arabinogalactans are genes involved in cell adhesion and cell expansion, and are highly expressed in immature fruit [45], while the function of arabinose 5-phosphate isomerase in eukaryotes is still poorly understood.

Genes involved in cell wall synthesis, and in particular cellulose synthesis (cellulose synthase, CeAs), were repressed in both affected inner (MDP0000289339) and outer (MDP0000314627) cortex. It was demonstrated that a decrease in the expression of $\operatorname{Ces} A$ in the early developmental stages of fruit growth, together with an increase in the expression of EXPs, are key regulators of cell wall biosynthesis during apple fruit development [46]. Additionally, two pectin methylesterase inhibitors (PMEI, MDP0000836165, and MDP0000616949) were down-regulated in the affected inner cortex, suggesting their putative role during abiotic stress exposure (e.g., cold, anoxia). PMEIs are cell wall proteins that regulate the activity of pectin methymesterases, and control the spatial distribution of esterified pectins in fruit [47].

\section{Genes involved in ethylene biosynthesis}

In agreement with previous studies in pear [4], a 1-aminocyclopropane-1-carboxylate oxidase (ACO; MDP0000200896) was down-regulated in the affected inner cortex as compared to the healthy tissue. ACO catalyses the last step in the ethylene biosynthetic pathway, in a reaction that needs both $\mathrm{O}_{2}$ and AsA as substrate. A reduced ACO expression in 'Golden Delicious' apples during $\mathrm{CA}$ storage has been reported [48], while high levels of $\mathrm{H}_{2} \mathrm{O}_{2}$ can inactivate $\mathrm{ACO}$ activity [49]. As such, the low expression of the specific $A C O$ gene copy observed in this study only in the affected inner cortex, can be explained by: 1) the severe hypoxic conditions in the inner part of the fruit compared to the outer part, 2) the possible increased amounts of $\mathrm{H}_{2} \mathrm{O}_{2}$, and/or 3) the reduced AsA content. The expression of $A C O$ is expected to be repressed by the treatment with 1-methylcyclopropene (1-MCP), as applied in this study. Nevertheless, the fact that the specific $A C O$ was only repressed in the affected inner cortex, and that its expression did not change over time, suggest that the expression of this gene copy is related to the disorder, and not to 1-MCP as such. Furthermore, the putative role of $A C O$ as a 'browning-biomarker' has been confirmed in stored apples not treated with 1MCP (see validation below). The expression of the other highly abundant ACO members, MDP0000195885 (chr10) and MDP0000200737 (chr5), did not differ between healthy and affected outer cortex (data not shown), suggesting a putative role of the $M d A C O$ presented here in the development of browning disorder in 'Braeburn' that should be further investigated.

\section{The role of polyphenol oxidases}

Regardless the cause of flesh browning (enzymatic after cutting or physiological due to stress), the eventual brown discolouration is usually the result of interactions between PPO activity and polyphenol contents. As discussed, the alterations in membrane permeability occurring during CA storage facilitates the release of both enzyme and substrate in the cytosol leading to the formation of brown pigments. As such, internal browning development under CA conditions could be explained by the compartmentalisation and activity of PPOs. A correlation between PPO activity and the incidence of internal browning has been previously reported in pineapple [50]. Additionally, reduced PPO activity may contribute to resistance against scald development in apples [51]. In this study, two PPOs were induced in both the inner (MdPPO-1, MDP0000249183) and the outer (MDP0000539552) cortex (Additional file 2: Tables S3-S4). In fact, MdPPO-1 was one of the most abundant transcripts found with RPKM values $>1700$ (Additional file 2: Table S3). Flesh browning in minimally processed apples has been linked to an induction of PPO expression [52]. Although browning occurred earlier than the induction of $P P O$ expression, the authors postulated that PPO was activated to stimulate the polyphenol signalling system playing an important role in the plant's defence against pests and insects [53]. In the end, the tissue breakdown induced by the abiotic stress of CA storage is not that different of similar defects induced by insect herbivory or microbial invasions thus triggering the same universal plant defence response.

\section{Putative biomarkers for browning disorder}

Using multivariate statistics to compare healthy and affected tissues with various degrees of browning development (from 
initiation to more severe stages), putative biomarkers to predict the incidence of browning were identified (Tables 1 and 2). Of them, 15 genes (Additional file 2: Table S5) were randomly selected for verification by qRT-PCR 1) on the same sample set as the RNA-Seq, and 2) on another 'validation' set that contained fruits stored for various periods at different CA conditions to test their broader potential (Figure 5, Additional file 1: Figure S4). Of the selected genes, $M d P D H$ (glycolysis) and $M d A C O$ (ethylene metabolism) were the only genes that were significantly induced or repressed, respectively, across all selected time points, in the affected inner cortex (Figure 5). Similarly, $M d S D H$ (mitochondrial ETC.) and MdHMGR (mevalonate pathway) were induced under the various conditions in the affected outer cortex. The other selected genes were only validated in one or two experiments (Additional file 1: Figure S4).

Interestingly, all the DEGs identified through the RNA-Seq analysis in the inner cortex were validated at four month storage, except for $M d C e s A$. The difference between the RNA-Seq experiment and the qRT-PCR validation set was the application of $1-\mathrm{MCP}$ and the lowest $\mathrm{CO}_{2}$ concentration in the first experiment. Most of the DEGs were also validated at CA storage for six months (except for MdPLA2), whereas only a few were verified at CA storage for two months (browning-inducing conditions at high $\mathrm{CO}_{2}$ levels). Nevertheless, there was a clear trend in agreement to the RNA-Seq results, suggesting that despite the different trigger (gas conditions), similar metabolic pathways are altered in the affected inner cortex. By contrast, DEGs between healthy and affected outer cortex were not verified in the validation set. Exceptions included $M d P K$ and $M d P P O-2$ that were validated as significant DEGs at six or four months, respectively. These findings, in combination with the observation that significant DEGs in the inner cortex were stable in the outer cortex (and vice-versa), as well as the limited overlap between the different cortex locations, clearly suggest a spatial variation in the regulation of browning induction, most likely related to the spatial $\mathrm{O}_{2}$ distribution.

\section{What makes apples turn brown?}

Prolonged postharvest storage at CA conditions can induce cellular oxidative stress by promoting ROS production and accumulation, thus causing oxidation of cellular components and loss of organelle integrity. The oxidative stress is expected to be more severe in the inner cortex, where the $\mathrm{O}_{2}$ concentration is around $0.5 \%$, compared to the $1.5-2 \%$ in the outer cortex (Figure $4 \mathrm{~A}$ ). Based on the presented RNA-Seq results, a conceptual model for browning development is proposed (Figure $4 \mathrm{~B}-\mathrm{C}$ ).

The changes in the redox state within affected tissues were evident in the whole fruit. In an attempt to control the excessive generation of ROS, several antioxidant-related genes were induced, including $A P X$, glutaredoxins and
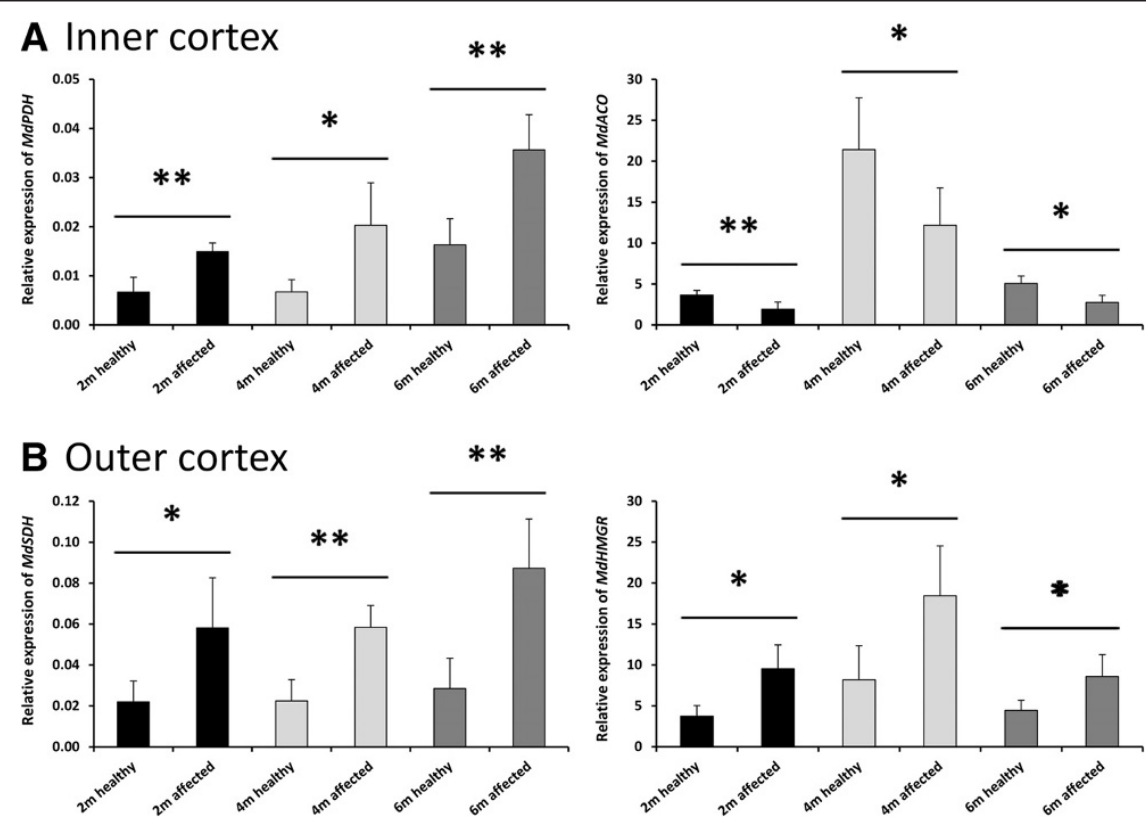

Figure 5 Gene expression studies using qRT-PCR. Relative expression of pyruvate dehydrogenase (MdPDH; MDP0000192364), and 1-aminocyclopropane-1-carboxylate oxidase (MdACO; MDP0000200896) in the inner cortex (A), and succinate dehydrogenase (MdSDH; MDP0000251581) and 3-hydroxy-3-methylglutaryl coenzyme a reductase (MdHMGR; MDP0000312032) in the outer cortex (B) of 'Braeburn' apples stored for two, four, or six months under various CA conditions. qRT-PCR values were normalized against the geometrical mean of ubiquitin (MDP0000154072) and actin (MDP0000886327). The error bars represent standard deviation of five biological replications. Significance of the mean relative gene expression of each group was tested with Student's t-test $\left({ }^{*} P<0.05\right.$, $\left.{ }^{* * P}<0.01\right)$ using the SAS software. 
thioredoxins (inner cortex), or CAT and SOD (outer cortex). Up-regulation of the ROS scavenging mechanism could have served as the trigger for the changes in metabolic and energy-related pathways. To cope with abiotic stress induced by the prolonged exposure to low temperature and low $\mathrm{O}_{2}$, a continuous energy supply to control ROS production and maintain membrane integrity, is vital. A clear induction of glycolytic pathway occurred in the affected inner cortex $(P M G)$, suggesting that pyruvate supply is not the ratelimiting factor, while the overall picture in the affected outer cortex was less clear with multiple DEGs being both induced and repressed. An increased flux to the TCA cycle occurred in the inner cortex (up-regulation of $P D H$ ), perhaps as an attempt to restore the energy potential. The TCA cycle itself was repressed in both tissues, and as such the rate of oxidative phosphorylation should be induced to maintain the energy balance. Indeed, the up-regulation of the ETC. in the outer cortex may have counteracted the effects of the down-regulated TCA cycle. By contrast, oxidative phosphorylation in the inner cortex was disturbed presumably as a result of the ultra-low $\mathrm{O}_{2}$ conditions (0.5\%), and, therefore, an alternative energy production path via fermentation may have been activated (induction of a putative lactate/malate dehydrogenase). Fermentation-related genes such as $A D H$ were repressed in the affected outer cortex. On the other hand, peroxisomal degradation of FAs, mediated by the $\beta$-oxidation cycle, help produce energy and acetyl-CoA. Up-regulation of FA oxidation occurred in both tissues, although an induction of acetyl-CoA related pathways (including mevalonate pathway and sphingolipid synthesis) only occurred in the outer cortex. Consequently, it is proposed that the energy status in the outer cortex may still efficiently balance the harmful effects of ROS accumulation presumably via increased energy production, whereas the reduced energy generation in the inner cortex may be insufficient to adverse the damage.

Less energy means incapacity to repair membranes, which, particularly in the inner cortex, are damaged as a result of induction of $\mathrm{a} / \mathrm{b}$ hydrolases and phospholipases. In turn, loosening of cellular compartmentalisation allows the release of $P P O$ s and phenols to the cytosol, triggering the actual discolouration reactions. Affected tissues showed higher $P P O$ expression serving as a generic plant defence response [52]. The effect of increased PPO activity can be reversed by AsA [14]. However, considering 1) the induction of AsA oxidation (inner cortex; high $A P X$ and apoplastic $A O$ ) and 2) the repression of AsA biosynthesis (outer cortex; low GPP) in the affected tissues, as well as 3 ) the repression of AsA recycling capacity (both; low DHAR) due to storage, it is postulated that AsA content is lower in the affected fruit. The changes in the redox state of the AsA pool may have served as the signal for other stress responses to hypoxic stress.
During browning development in stored apples, genes involved in cell wall loosening including AO, XET, PLAs and EXPs are mostly induced, while genes involved in cell wall synthesis or strengthening, such as $\mathrm{CeAs}$ or PMEIs, are mostly repressed. This observation suggest for the first time that susceptibility to postharvest disorders such as internal browning are somehow linked to cell wall modifications, similar to those observed during fruit softening, or the response to biotic stress. This may be also linked to the formation of cavities observed at severely affected apples. Apart from the lack of overlap between the sets of DEGs identified in each cortex location as a response to the oxidative stress, several pathways were strongly altered in a tissue-specific manner (Figure 2). Specifically, genes involved in lipid metabolism, SM, and cell wall modifications were highly modified in the affected inner cortex, while stress-related or energy-related genes were mostly altered in the outer cortex. This is presumably due to the spatial distribution of $\mathrm{O}_{2}$ induced by the fruit's microstructure [7], and the resulting gas exchange properties (Figure 4A).

\section{Conclusions}

This is the first report of a complete quantitative transcriptome analysis of internal browning disorder in apples stored under CA conditions revealing numerous novel regulatory candidate genes, and confirming results from proteomic approaches in other pome fruit, such as pear. Results indicated alterations in several metabolic pathways occurring during postharvest storage of apple, including the repression of the TCA cycle, as well as the up-regulation of the ETC. and the FA oxidation. These alterations can be seen as an attempt to control the excessive generation of ROS induced by the storage conditions eventually lead to browning development in a tissue-specific manner. The RNA-Seq results provided here may serve as a 'genetic' roadmap of fruit-tissue specific changes to postharvest-induced oxidative stress, clearly suggesting spatial differences in the regulation of browning. This study can serve as starting point for additional proteomic and metabolomic screenings to create a complete view on the development of the disorder at the various 'omic' levels. Further validation is required to assess the importance of the proposed candidate genes as potential markers to predict the risk of browning incidence in apples during CA storage.

\section{Methods}

\section{Plant material and postharvest conditions}

Trees of cv 'Braeburn' (clone Hillwell), grafted on a M9 rootstock, were grown in the orchard of the experimental tree fruit research station (RSF-PCfruit) in Sint-Truiden, Belgium. Apples were harvested on October 26, 2011, the commercial picking date for long-term storage of 'Braeburn' 
as determined by the Flanders Centre of Postharvest Technology. Apples were stored for four months at $1^{\circ} \mathrm{C}$ under $\mathrm{CA}$ of $3 \% \mathrm{O}_{2}$ and $0.7 \% \mathrm{CO}_{2}$ receiving commercial application of 1-MCP. The 1-MCP (SmartFreshTM, AgroFresh Inc. Spring House, PA, USA) treatment was done by exposing the fruits to 1-MCP (625 ppb) in airtight containers for $24 \mathrm{~h}$. Under the specified CA conditions, a sufficient variability in the occurrence of visible browning symptoms was detected.

\section{Fruit sampling and browning assessment}

In total, 20 individual fruit were sampled for the sequencing experiment. Four fruit were sampled at harvest, and after four of months storage another 16 fruit were sampled. In each one of them, $1 \mathrm{~cm}$ thick slices were cut through the equator of the fruit. From each fruit, five tissue samples of $1 \mathrm{~cm}$ diameter were taken from the inner and the outer cortex (Additional file 1: Figure S1), immediately frozen, crushed in liquid nitrogen and stored at $-80^{\circ} \mathrm{C}$. To assess browning, pictures were taken from the complementary tissue slice immediately after cutting using a digital camera and controlled light conditions. For each tissue sample a visual BI was calculated using an in-house developed MATLAB program (Matlab R2010, The MathWorks, Inc., Natick, MA, USA) as described previously [2]. The colour scale was based on ten classes ranging from yellow (one) to brown (ten). Tissues were classified as healthy (low BI) or affected (high BI) (Additional file 1: Figure S1; Additional file 2: Table S7). Three groups of apples were identified: 1 ) those with both healthy inner and outer cortex, 2) those with only inner cortex affected, and 3) those with both inner and outer cortex affected. Tissues from all three groups of apples were taken to cover the initiation and development of the disorder in a tissue-specific manner.

\section{RNA extraction, library construction, and sequencing}

Total RNA was extracted from all 20 fruit (4 replicate fruit collected at harvest and 16 after storage) from both inner and outer cortex tissue samples as shown in Additional file 1: Figure S1. The replicate fruit collected after storage were further classified as healthy or affected, as shown in Additional file 2: Table S1. Ground tissue samples $(300 \mathrm{mg}$ ) were homogenized in $800 \mu \mathrm{L}$ of extraction buffer containing cetyl-trimethyl-ammonium bromide, according to [54]. The mixture was incubated at $65^{\circ} \mathrm{C}$ for $10 \mathrm{~min}$ with occasional mixing by inversion. Chloroform $(800 \mu \mathrm{L})$ was added and mixed by inversion, and the mixture was centrifuged at $14,000 \mathrm{rpm}$ for $10 \mathrm{~min}$ at room temperature. The supernatant was mixed with a half volume of ethanol, loaded and washed through the RNeasy mini kit column (Qiagen). The purity of total RNA extracted was determined in NanoDrop 2000
(Thermo Scientific), and the integrity was checked by electrophoresis (Gel Doc EZ Imager; Bio-Rad). Strand specific mRNA-Seq libraries were made using $2 \mu \mathrm{g}$ of DNase-treated total RNA and T4 RNA ligase 1 adenylated adapters [55]. The purified libraries were quantified and $20 \mathrm{ng}$ of each used for sequencing. Samples were sequenced on an Illumina HiSeq2000 (Illumina, San Diego, CA) at the Weill Medicine School Sequencing Facility (Cornell University, NY, USA) with a 51-bp single-end read length. Libraries were spread over four lanes, avoiding biological replicates in the same lane. The sequence files were generated using the Illumina pipeline in software CASAVA v1.8 in Sanger FASTQ format and are available in the European Nucleotide Archive (http://www.ebi.ac.uk/ ena/data/view/PRJEB6096).

\section{Data processing and differential gene expression analysis} Quality control of the short single-end raw reads for sequence contaminants was performed using the Fastqc module in Galaxy (http://main.g2.bx.psu.edu/) [56]. Reads were then analysed using the RNA-Seq analysis tools of the CLC Genomics Workbench software v6.5 (CLC bio, Aarhus, Denmark), and mapped against the Malus consensus CDS set (http://www. rosaceae.org/). No more than two mismatches per read were allowed. Only unique mappings were counted for expression analyses.

Gene expression levels were normalized using RPKM values. The RPKM values of the 63,541 genes of healthy and affected, inner and outer cortex, were explored with principal component analysis to detect outliers using The Unscrambler (v10.1, Camo, Trondheim, Norway). Two outlier samples were detected and removed. The PLS-DA in combination with an iterative jack-knifing procedure was performed on the inner and outer cortex samples separately, to identify significant DEGs between healthy and affected tissues. Specifically, RPKM values were used as predictor variables and the class distinction (healthy-affected) as response variables. Through cross validation, using the uncertainty test with the optimal number of factors, a set of the most significant predictor variables was selected. This iterative process was repeated until the percentage of variability explained by the reduced set of genes no longer improved. The resulting set of DEGs was filtered based on the p-value for beta-coefficients for the model $(\mathrm{p}<0.05)$ and on the fold change $(>1.5$ or $<-1.5)$ in RPKM between the two classes. To ensure that the final gene selection only contained browning-related transcripts and not the more general ripening or storage-related ones, DEGs also showing up in healthy apples when comparing harvest to four month storage were removed from the dataset (Additional file 2: Table S2). 
For each DEG, the latest GO annotation vocabulary for cellular component, biological process and molecular function, was obtained using Blast2GO v.2.7.0 [57]. Default parameter settings were applied and the GOslim option was set to reduce the number of functional classes. In addition, DEGs were uploaded to the Mercator webtool (http://mapman.gabipd.org/web/guest/app/mercator) to assign bincode mapping [58], and visualized using MapMan (v.3.6, http://mapman.gabipd.org/web/guest/mapman) [59]. Default parameters were retained, and Blast cut-off was set at 50 .

\section{Technical and functional validation}

In total, 15 candidate genes differentially expressed between affected and healthy fruit were selected for qRT-PCR validation making sure to cover multiple metabolic pathways. Specific primers (Additional file 2: Table S5) were designed using Primer3 web tool (http://bioinfo.ut.ee/primer3/) and verified against the Malus predicted consensus gene set using the BLAST function of the Genome Database for Rosaceae. The transcriptional profiles of the selected genes were analysed by qRT-PCR using the SYBR Green I technology on a Rotor Gene Q (Qiagen). The purified RNA used for RNA-Seq was reverse transcribed into cDNA using the QuantiTect Reverse Transcription Kit (Qiagen). All qRTPCR reactions contained $500 \mathrm{ng} / \mu \mathrm{l}$ of cDNA template, $7.5 \mathrm{~mL}$ of Absolute QRT-PCR SYBR Green Mix (Thermo Fisher Scientific), and $0.25 \mu \mathrm{M}$ primer pairs, in a final volume of $15 \mu \mathrm{l}$. The same cycling conditions, melting curve analysis and criteria of acceptance for reaction efficiency were applied as described previously [60]. All expression data were normalized against the geometric mean of the expression of two stable reference genes, ubiquitin (MDP0000154072) and actin (MDP0000886327).

The selected candidate genes were independently validated on apples (cv 'Braeburn') stored for two, four and six months under various $\mathrm{CA}$ conditions (Additional file 2: Table S8). RNA isolation, cDNA synthesis, and qRTPCR analysis were performed on samples from the inner and outer cortex of these independent fruit as described above. Based on their BI (Additional file 2: Table S8), tissues were classified as healthy and affected, and the DEGs between the two class distinctions $\left(" p<0.05,{ }^{* * *} p<0.01\right.$ and $\left.{ }^{* * * *} p<0.001\right)$ were identified based on the t-test using the Statistical Analysis Software (SAS Enterprise Guide 4.2; SAS Institute Inc.).

\section{Availability of supporting data}

The data sets supporting the results of this article are available in the European Nucleotide Archive (http://www.ebi. ac.uk/ena/data/view/PRJEB6096).

\section{Additional files}

\begin{abstract}
Additional file 1: Figure S1. Cross-section of apples with various degress of browning incidence. Figure S2. MapMan bins. Figure S3. Overview of metabolic pathways of differentially expressed genes between healthy and affected tissues in MapMan. Figure S4. Validation of RNA-Seq results by qRT-PCR.

Additional file 2: Table S1. Reads and their mapping on the Malus consensus sequences for inner and outer cortex. Table S2. Storage-related genes that were excluded from the analysis of RNA-Seq of browning disorder. Table S3. Differentially expressed genes between healthy and affected inner cortex. Table S4. Differentially expressed genes between healthy and affected outer cortex. Table S5. Primer sequences used for validation of RNA-Seq results by qRT-PCR. Table S6. Gene expression values (RPKM) of the different dehydroascorbate reductases (DHAR) as revealed by RNA-Seq. Table S7. The browning index (BI) of inner and outer cortex of apples used for RNA-Seq. Table S8. The browning index (BI) of inner and outer cortex of the validation set.
\end{abstract}

\section{Abbreviations}

ACO: 1-aminocyclopropane-1-carboxylate oxidase; ACT: Acyl-CoA thioesterase; ACX: Acyl-CoA oxidase; ADH: Alcohol dehydrogenase; AO: Ascorbate oxidase; APX: Ascorbate peroxidase; AsA: L-ascorbic acid; Bl: browning index; CA: Controlled atmosphere; CAT: Catalase; CDS: Coding sequences; CM: Chorismate mutase; CeAs: Cellulose synthase; CS: Citrate synthase; DEGs: Differentially expressed genes; DHA: Dehydroascorbate;

$D H A R$ : Dehydroascorbate reductase; ETC: Electron transport chain; EXP: Alpha expansin; FA: Fatty acids; GO: Gene ontology; GPP: L-galactose-1-phosphate phosphatase; HMGR: 3-hydroxy-3-methylglutaryl-CoA reductase; $M D H$ : Malate dehydrogenase; PDH: Pyruvate dehydrogenase; PEPC: Phosphoenolpyruvate carboxylase; PK: Pyruvate kinase; PLA2: Phospholipase a2; PLS-DA: Partial least squares discriminant analysis; PMEl: Pectin methylesterase inhibitor; PMG: Phosphoglyceratemutase; PPO: Polyphenol oxidase; RNA-Seq: RNA sequencing; ROS: Reactive oxygen species; RPKM: Reads per kilobase of exon per million mapped reads; SDH: Succinate dehydrogenase; SM: Secondary metabolism; SOD: Superoxide dismutase; TCA: Tricarboxylic acid; XET: Xyloglucanendotransglucosylase/hydrolase.

\section{Competing interests}

The authors declare that they have no competing interests.

\section{Authors' contributions}

IM, MLATMH and BMN designed the experiment. JWJ, CBW, RJS, NEG, JJG and RDR contributed to the conception and design of the experiment. KB and DH performed browning assessments. QTH performed simulation of the gas distribution. JJG and NEG arranged for the sequencing of the samples. IM performed RNA extractions, the quantitative RT-PCR, and carried out the bioinformatics analysis. IM and MLATMH performed the statistical data analysis and drafted the manuscript. JWJ, CBW, RJS, RDR, NEG, and JJG were involved in the interpretation of data and revised the manuscript for important intellectual content. MLATMH and BMN were project co-ordinators and supervisors. All authors read and approved the final manuscript.

\section{Acknowledgements}

This work was funded by the IWT, the Flemish government agency for Innovation by Science and Technology (IWT project 080527), the Research Council of the University of Leuven (project OT 12/055), the Research Foundation Flanders (FWO project G.0645.13), the EU (COST Action FA1106, 'QualityFruit') and executed in conjunction with the USDA-ARS project 59-5350-1-103 F.

\section{Author details}

'Division of Mechatronics, Biostatistics and Sensors, Department of Biosystems (BIOSYST), KU Leuven, Willem de Croylaan 42, bus 2428, Leuven 3001, Belgium. ${ }^{2}$ Flanders Centre of Postharvest Technology, Willem de Croylaan 42, Leuven 3001, Belgium. ${ }^{3}$ Fruit Tree Research Laboratory, US Department of Agriculture/Agriculture Research Service, Wenatchee, WA 9880, USA. ${ }^{4}$ Department of Horticulture, Cornell University, Ithaca, NY 14853, USA. ${ }^{5}$ Boyce Thompson Institute for Plant Research, Cornell University, Ithaca, NY 14853, USA. ${ }^{6}$ The New Zealand Institute for Plant \& Food Research 
Limited, Mount Albert Research Centre, Private Bag 92169, Auckland 1142 New Zealand. ${ }^{7}$ The University of Auckland, Private Bag 92019, Auckland 1142 New Zealand. ${ }^{8}$ Plant, Soil, and Nutrition Laboratory, US Department of Agriculture/Agriculture Research Service, Ithaca, NY 14853, USA.

Received: 8 September 2014 Accepted: 7 November 2014 Published online: 28 November 2014

\section{References}

1. Elgar HJ, Burmeister DM, Watkins CB: Storage and handling effects on a CO2-related internal browning disorder of "Braeburn" apples. Hortscience 1998, 33:719-722

2. Hatoum D, Buts $K$, Hertog M: Effects of pre-and postharvest factors on browning in Braeburn. Hortic Sci 2013, 41:19-26.

3. Franck C, Lammertyn J, Ho QT, Verboven P, Verlinden B, Nicolaï BM: Browning disorders in pear fruit. Postharvest Biol Technol 2007, 43:1-13.

4. Pedreschi R, Vanstreels E, Carpentier S, Hertog M, Lammertyn J, Robben J, Noben J-P, Swennen R, Vanderleyden J, Nicolaï BM: Proteomic analysis of core breakdown disorder in Conference pears (Pyrus communis L.). Proteomics 2007, 7:2083-2099.

5. Pedreschi R, Hertog M, Robben J, Lilley KS, Karp NA, Baggerman G, Vanderleyden J, Nicolaï B: Gel-based proteomics approach to the study of metabolic changes in pear tissue during storage. J Agric Food Chem 2009, 57:6997-7004

6. Jung S-K, Watkins CB: Involvement of ethylene in browning development of controlled atmosphere-stored "Empire" apple fruit. Postharvest Biol Technol 2011, 59:219-226.

7. Herremans $E$, Verboven $P$, Bongaers $E$, Estrade $P$, Verlinden $B E$, Wevers $M$ Hertog ML ATM, Nicolai BM: Characterisation of "Braeburn" browning disorder by means of X-ray micro-CT. Postharvest Biol Technol 2013, 75:114-124.

8. Ho QT, Verboven P, Verlinden BE, Schenk A, Delele MA, Rolletschek H, Vercammen J, Nicolaï BM: Genotype effects on internal gas gradients in apple fruit. J Exp Bot 2010, 61:2745-2755.

9. Ho QT, Verlinden BE, Verboven P, Nicolaï BM: Gas diffusion properties at different positions in the pear. Postharvest Biol Technol 2006, 41:113-120.

10. Ho QT, Verboven $P$, Verlinden BE, Herremans E, Wevers M, Carmeliet J Nicolaï BM: A three-dimensional multiscale model for gas exchange in fruit. Plant Physio/ 2011, 155:1158-1168.

11. Ho QT, Verboven P, Verlinden BE, Schenk A, Nicolaï BM: Controlled atmosphere storage may lead to local ATP deficiency in apple. Postharvest Biol Technol 2013, 78:103-112.

12. Tomás-Barberán F, Espín JC: Phenolic compounds and related enzymes as determinants of quality in fruits and vegetables. J Sci Food Agric 2001, 81:853-876

13. Franck C, Baetens M, Lammertyn J, Scheerlinck N, Davey M, Nicolaï B: Ascorbic acid mapping to study core breakdown development in 'Conference' pears. Postharvest Biol Technol 2003, 30(2):133-142.

14. Chow Y-N, Louarme L, Bonazzi C, Nicolas J, Billaud C: Apple polyphenoloxidase inactivation during heating in the presence of ascorbic acid and chlorogenic acid. Food Chem 2011, 129:761-767.

15. Velasco R, Zharkikh A, Affourtit J, Dhingra A, Cestaro A, Kalyanaraman A, Fontana P, Bhatnagar SK, Troggio M, Pruss D, Salvi S, Pindo M, Baldi P, Castelletti S, Cavaiuolo M, Coppola G, Costa F, Cova V, Dal Ri A, Goremykin V, Komjanc M, Longhi S, Magnago P, Malacarne G, Malnoy M, Micheletti D, Moretto M, Perazzolli M, Si-Ammour A, Vezzulli S, et al: The genome of the domesticated apple (Malus $\times$ domestica Borkh.). Nat Genet 2010, 42:833-839.

16. Krost C, Petersen R, Lokan S, Brauksiepe B, Braun P, Schmidt ER: Evaluation of the hormonal state of columnar apple trees (Malus $\mathrm{x}$ domestica) based on high throughput gene expression studies. Plant Mol Biol 2013, 81:211-220.

17. Foster TM, Watson AE, Hooijdonk BM, Schaffer RJ: Key flowering genes including FT-like genes are upregulated in the vasculature of apple dwarfing rootstocks. Tree Genet Genomes 2013, 10:189-202.

18. Gusberti M, Gessler C, Broggini GAL: RNA-Seq analysis reveals candidate genes for ontogenic resistance in Malus-Venturia pathosystem. PLoS One 2013, 8:e78457.

19. Gapper NE, Rudell DR, Giovannoni JJ, Watkins CB: Biomarker development for external $\mathrm{CO} 2$ injury prediction in apples through exploration of both transcriptome and DNA methylation changes. AoB Plants 2013, 5:plt021.
20. Bouvier F, Camara B: The Role of Plastids in Ripening Fruits. In Struct Funct Plast. Edited by Wise RW, Hoober JK. Dordrecht, The Netherlands: Springer; 2007:419-432.

21. Westram A, Lloyd JR, Roessner U, Riesmeier JW, Kossmann J: Increases of 3-phosphoglyceric acid in potato plants through antisense reduction of cytoplasmic phosphoglycerate mutase impairs photosynthesis and growth, but does not increase starch contents. Plant Cell Environ 2002, 25:1133-1143.

22. Tovar-Mendez A, Miernyk JA, Randall DD: Regulation of pyruvate dehydrogenase complex activity in plant cells. Eur J Biochem 2003, 270:1043-1049.

23. Lehmann M, Schwarzländer M, Obata T, Sirikantaramas S, Burow M, Olsen CE, Tohge T, Fricker MD, Møller BL, Fernie AR, Sweetlove L, Laxa M: The metabolic response of Arabidopsis roots to oxidative stress is distinct from that of heterotrophic cells in culture and highlights a complex relationship between the levels of transcripts, metabolites, and flux. Mol Plant 2009, 2:390-406.

24. Møller IM, Jensen PE, Hansson A: Oxidative modifications to cellular components in plants. Annu Rev Plant Biol 2007, 58:459-481.

25. Huang S, Millar AH: Succinate dehydrogenase: the complex roles of a simple enzyme. Curr Opin Plant Biol 2013, 16:344-349.

26. Affourtit C, Krab K, Graeme R, Whitehouse DG, Anthony L, Leach GR, Moore AL: Enzyme catalysis and regulation: New Insights into the Regulation of Plant Succinate Dehydrogenase. J Biol Chem 2001, 276:32567-32574.

27. Saquet AA, Streif J, Bangerth F: Energy metabolism and membrane lipid alterations in relation to brown heart development in "Conference" pears during delayed controlled atmosphere storage. Postharvest Biol Technol 2003, 30:123-132.

28. Testerink C, Munnik T: Molecular, cellular, and physiological responses to phosphatidic acid formation in plants. J Exp Bot 2011, 62:2349-2361.

29. Graham IA, Eastmond PJ: Pathways of straight and branched chain fatty acid catabolism in higher plants. Prog Lipid Res 2002, 41:156-181.

30. Berkey R, Bendigeri D, Xiao S: Sphingolipids and plant defense/disease: the "death" connection and beyond. Front Plant Sci 2012, 3(April):68.

31. Davey MW, Sanmartin M, Van MM, Inze D, Kanellis A, Smirnoff N, Benzie IJJ, Strain JJ, Favell D, Fletcher J: Review Plant L -ascorbic acid: chemistry , function, metabolism , bioavailability and effects of processing. 2000, 860:825-860.

32. Mellidou I, Chagne D, Laing WA: Allelic variation in paralogs of GDP-L-galactose phosphorylase is a major determinant of vitamin $\mathrm{C}$ concentrations in apple fruit. 2012, 160:1613-1629.

33. Davey MW, Kenis K, Keulemans J: Genetic control of fruit vitamin C contents. Plant Physiol 2006, 142:343-351.

34. Loannidi E, Kalamaki MS, Engineer C, Pateraki I, Alexandrou D, Mellidou I, Giovannonni J, Kanellis AK: Expression profiling of ascorbic acid-related genes during tomato fruit development and ripening and in response to stress conditions. J Exp Bot 2009, 60:663-678.

35. Shi $Y$, Jiang $L$, Zhang $L$, Kang $R$, $Y u$ Z: Dynamic changes in proteins during apple (Malus $\mathrm{x}$ domestica) fruit ripening and storage. Hortic Res 2014, 1(December 2013):6.

36. Valentines MC, Vilaplana $R$, Torres $R$, Usall J, Larrigaudière C: Specific roles of enzymatic browning and lignification in apple disease resistance. Postharvest Biol Technol 2005, 36:227-234.

37. Leivar P, Antolín-Llovera M, Ferrero S, Closa M, Arró M, Ferrer A, Boronat A, Campos $\mathrm{N}$ : Multilevel control of Arabidopsis 3-hydroxy-3-methylglutaryl coenzyme A reductase by protein phosphatase 2A. Plant Cell 2011, 23:1494-1511.

38. Rupasinghe HPV, Almquist KC, Paliyath G, Murr DP: Cloning of hmg1 and hmg2 cDNA encoding 3-hydroxy-3-methylglutaryl coenzyme A reductase (HMGR) and their expression and activity in relation to alpha-farnesene synthesis in apple. Plant Phys Biochem 2001, 39:933-947.

39. Ju Z, Yuan Y, Liu C, Zhan S, Wang M: Relationships among simple phenol, flavonoid and anthocyanin in apple fruit peel at harvest and scald susceptibility. Postharvest Biol Technol 1996, 8:83-93.

40. Pignocchi $\mathrm{C}$, Foyer $\mathrm{CH}$ : Apoplastic ascorbate metabolism and its role in the regulation of cell signalling. Curr Opin Plant Biol 2003, 6:379-389.

41. Rose J, Bennett A: Cooperative disassembly of the cellulose-xyloglucan network of plant cell walls: parallels between cell expansion and fruit ripening. Trends Plant Sci 1999, 4:176-183.

42. Johnston JW, Hewett EW, Hertog MLATM, Harker FR: Harvest date and fruit size affect postharvest softening of apple fruit. J Hortic Sci Biotechnol 2002, 77:355-360 
43. Zhong Y, Chen J, Feng H, Kuang J, Xiao R, Ou M, Xie H, Lu W, Lin H: Expansin and XET genes are differentially expressed during aril breakdown in harvested longan fruit. J Am Soc Hort Sci 2008, 133:462-467.

44. Marin-Rodriguez MC: Pectate lyases, cell wall degradation and fruit softening. J Exp Bot 2002, 53:2115-2119.

45. Guo S, Liu J, Zheng Y, Huang M, Zhang H, Gong G, He H, Ren Y: Characterization of transcriptome dynamics during watermelon fruit development : sequencing, assembly, annotation and gene expression profiles. BMC Genomics 2011, 12:454.

46. Guerriero G, Giorno F, Folgado R, Printz B, Baric S, Hausman J-F: Callose and cellulose synthase gene expression analysis from the tight cluster to the full bloom stage and during early fruit development in Malus $\times$ domestica. J Plant Res 2014, 127:173-183.

47. Reca IB, Lionetti V, Camardella L, D'Avino R, Giardina T, Cervone F, Bellincampi D: A functional pectin methylesterase inhibitor protein (SolyPMEI) is expressed during tomato fruit ripening and interacts with PME-1. Plant Mol Biol 2012, 79:429-442.

48. Gorny JR, Kader AA: Controlled-atmosphere Suppression of ACC Synthase and ACC Oxidase in "Golden Delicious" Apples during Long-term Cold Storage. J Am Soc Hort Sci 1996, 121:751-755.

49. Wang KL, Li H, Ecker JR: Ethylene Biosynthesis and Signaling Networks. Plant Cell 2002, 14:S131-S151.

50. Hong K, Xu H, Wang J, Zhang L, Hu H, Jia Z, Gu H, He Q, Gong D: Quality changes and internal browning developments of summer pineapple fruit during storage at different temperatures. Sci Hortic 2013, 151:68-74.

51. Lurie S, Watkins CB: Superficial scald, its etiology and control. Postharvest Biol Technol 2012, 65:44-60.

52. Di Guardo M, Tadiello A, Farneti B, Lorenz G, Masuero D, Vrhovsek U, Costa $G$, Velasco R, Costa F: A multidisciplinary approach providing new insight into fruit flesh browning physiology in apple (Malus $x$ domestica Borkh.). PLoS One 2013, 8:e78004

53. Constabel CP, Barbehenn R: Defensive Roles of Polyphenol Oxidase in Plants. In Induced Plant Resistance to Herbivory. Edited by Schaller A. Dordrecht, The Netherlands: Springer Verlag; 2008:253-269.

54. Gasic K, Hernandez A, Korban SS: RNA extraction from different apple tissues rich in polyphenols and polysaccharides for CDNA library construction. Plant Mol Biol Report 2004, 22:437-438.

55. Chen Y-R, Zheng Y, Liu B, Zhong S, Giovannoni J, Fei Z: A cost-effective method for Illumina small RNA-Seq library preparation using T4 RNA ligase 1 adenylated adapters. Plant Methods 2012, 8:41-46.

56. Goecks J, Nekrutenko A, Taylor J: Galaxy: a comprehensive approach for supporting accessible, reproducible, and transparent computational research in the life sciences. Genome Biol 2010, 11:R86

57. Conesa A, Götz S, García-Gómez JM, Terol J, Talón M, Robles M: Blast2GO: a universal tool for annotation, visualization and analysis in functional genomics research. Bioinformatics 2005, 21:3674-3676.

58. Lohse M, Nagel A, Herter T, May P, Schroda M, Zrenner R, Tohge T, Fernie AR, Stitt M, Usadel B: Mercator: a fast and simple web server for genome scale functional annotation of plant sequence data. Plant Cell Environ 2014, 37(5):1250-1258.

59. Usadel B, Poree F, Nagel A, Lohse M, Czedik-Eysenberg A, Stitt M: A guide to using MapMan to visualize and compare Omics data in plants: a case study in the crop species, Maize. Plant Cell Environ 2009, 32:1211-1229.

60. Mellidou I, Keulemans J, Kanellis AK: Regulation of fruit ascorbic acid concentrations during ripening in high and low vitamin $\mathrm{C}$ tomato cultivars. BMC Plant Biol 2012, 12:239-258.

\section{Submit your next manuscript to BioMed Central and take full advantage of:}

- Convenient online submission

- Thorough peer review

- No space constraints or color figure charges

- Immediate publication on acceptance

- Inclusion in PubMed, CAS, Scopus and Google Scholar

- Research which is freely available for redistribution

Submit your manuscript at www.biomedcentral.com/submit
C) Biomed Central 